\title{
Oxidation of Cashew Tree Gum Exudate Polysaccharide with TEMPO Reagent
}

\author{
Pablyana L. R. Cunha, ${ }^{a}$ Jeanny S. Maciel, ${ }^{a}$ Maria Rita Sierakowski, ${ }^{b}$ Regina C. M. de Paula ${ }^{a}$ and \\ Judith P. A. Feitosa ${ }^{*, a}$ \\ ${ }^{a}$ Departamento de Química Orgânica e Inorgânica, Universidade Federal do Ceará, \\ CP 12200, 60455-760 Fortaleza-CE, Brazil \\ ${ }^{b}$ Departamento de Química, Universidade Federal do Paraná, Curitiba-PR, Brazil
}

\begin{abstract}
A goma do cajueiro, um polissacarídeo exsudado da árvore Anacardium ocidentale, foi oxidada com o reagente TEMPO e o produto (CGOX) foi caracterizado por técnicas espectroscópicas (FT-IR e RMN), análises cromatográficas (HPLC e GPC), viscosidade e análise térmica (TGA). O rendimento do produto da reação foi de $96 \%$. O teor de ácido urônico da goma nativa $(7,2 \%)$ aumentou para $36 \%$ após a reação. O grau de oxidação, tendo como base as unidades de galactose e glucose livres, foi de $68 \%$. Os dados de RMN mostraram que a oxidação ocorreu preferencialmente nos carbonos primários das unidades de galactose. A grande diferença entre o valor esperado de $\eta_{\mathrm{CGOX}} / \eta_{\mathrm{CG}}$ e o valor observado indica que a degradação, durante a oxidação, ocorreu em grande extensão. A presença de impurezas orgânicas e inorgânicas no novo polieletrólito foi detectada por TGA. A goma do cajueiro após a modificação com TEMPO apresentou mais baixa estabilidade térmica que a goma nativa, indicada pelos valores de temperatura inicial de decomposição e IPDT.
\end{abstract}

Cashew gum (CG), an exudate polysaccharide from Anacardium ocidentale trees, was oxidized with TEMPO reagent and the 7product (CGOX) characterized by spectroscopic techniques (FTIR and NMR), chromatographic analyses (HPLC and GPC), viscosity measurements and thermal analysis (TGA). The yield of the reaction product was $96 \%$. The uronic acid content in starting gum $(7.2 \mathrm{~m} \%)$ was increased to $36 \mathrm{~m} \%$. The degree of oxidation based on free galactose and glucose units was $68 \%$. NMR data show that oxidation occurred preferentially at primary carbons of galactose units. High degradation degree after oxidation was estimated by the difference on the expected and observed $\eta_{\mathrm{CGOX}} / \eta_{\mathrm{CG}}$ ratio. The presence of organic and inorganic impurities in the new polyelectrolyte was detected by TGA. A less thermally stable cashew gum is formed after the oxidation with TEMPO based on initial decomposition temperature and IPDT.

Keywords: cashew gum, oxidation, TEMPO, Anacardium occidentale, polysaccharide

\section{Introduction}

In the recent decade, catalytic oxidation of carbohydrates using the stable nitroxyl radical 2,2,6,6tetramethylpiperidine-1-oxyl (TEMPO) has become one of the most promising procedures to convert polysaccharides into the corresponding polyuronic acids. ${ }^{1,2}$ Contrary to enzymatic or metal-catalyzed oxidation, the TEMPOoxidation process is highly effective in the conversion of high molecular weight polysaccharides. Direct oxidation of hydroxyl groups provides interesting routes for the introduction of carbonyl and carboxyl groups into polysaccharides. ${ }^{2}$ The TEMPO presents many advantages

*e-mail: judith@dqoi.ufc.br as reagent for oxidation, such as chemical stability in the presence of air, light or moisture, and the possibility of storage without special conditions, differently of a great number of reagent used for oxidation. ${ }^{3}$

The conversion of primary alcohols to carboxylates proceeds via a reactive aldehyde-intermediate, which is present at low concentration throughout the oxidation. ${ }^{1}$ Regeneration of the nitrosonium salt, which is the active oxidizing species, takes places in situ by the use of a suitable primary oxidant, e.g. sodium hypochlorite with catalytic amounts of sodium bromide. ${ }^{4} \mathrm{~A}$ highly selective oxidation of C-6 primary hydroxyl to carboxylic groups can be achieved in aqueous solution of polysaccharides at $\mathrm{pH}$ 9-11 with $\mathrm{NaClO}$ and catalytic amounts of TEMPO and $\mathrm{NaBr}$. The corresponding polyuronic acids were thus 
obtained in high yields. ${ }^{5}$ A schematic representation of TEMPO oxidation process is depicted in Figure 1.

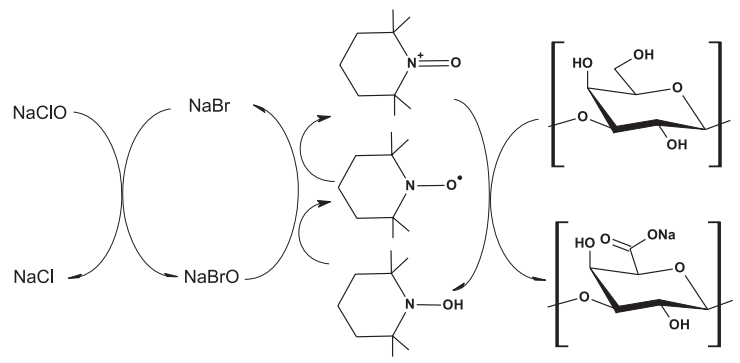

Figure 1. Schematic representation of TEMPO oxidation process of galactan.

Several publications describe procedures for oxidation with TEMPO of various polysaccharides, such as starch, ${ }^{5}$ galactomannans, ${ }^{7,8}$ inulin and pullulan, ${ }^{8}$ chitin, ${ }^{9}$ chitosan, potato amylose and amylopectin, ${ }^{10}$ hyaluronan, ${ }^{11}$ scleroglucan, ${ }^{12}$ galactoxyloglucan. ${ }^{13}$ A number of applications have been described for these oxidized carbohydrates. They rely on some of their specific properties, ranging from gelation, to complexation, antiflocculation, adhesion, as well as varied biological activity. ${ }^{7,14}$

Cashew gum (CG) is an exudate polysaccharide from Anacardium occidentale trees. Our group has been studied this gum since $1993 .{ }^{15}$ The gum was characterized as a heteropolysaccharide containing galactose (72$73 \%)$, glucose $(11-14 \%)$, arabinose $(4.6-5 \%)$, rhamnose $(3.2-4 \%)$ and glucuronic acid (4.7-6.3\%) in mass $\% .^{16,17}$ $\mathrm{CG}$ is mainly composed of three types of galactan units within the core, linked by $\mathrm{C}-1$ and C-3; C-1 and C- 6 and C-1, C-3 and C-6. The glucose is present as a side chain, with up to five units long. ${ }^{17}$

Some application based on CG has been proposed in last few years, such as superabsorbent hydrogel as soil conditioner, ${ }^{18}$ polyelectrolyte complex with chitosan for drug delivery. ${ }^{19}$ The polysaccharide has also been modified by carboxymethylation with monochloroacetic acid as the etherifying agent. ${ }^{20}$ Brazil has approximately 680,000 ha of planted area with cashew nut tree. ${ }^{21}$ The average production of gum/tree/year is $700 \mathrm{~g},{ }^{22}$ with the potential annual CG production of 38 thousands of ton.

The purpose of this work is to prepare and characterize an oxidized cashew gum in order to increase the polyelectrolyte character and amplify the possibilities of CG application.

\section{Experimental}

\section{Materials}

Crude samples from cashew gum (CG) were collected from native trees at Fortaleza, Ceará, Brazil. They were purified as a sodium salt using the method previously described. ${ }^{17,23}$ Nodules free of bark were selected and dissolved in distilled water at room temperature to give a $5 \%(\mathrm{~m} / \mathrm{v})$ solution. The solution $\mathrm{pH}$ was adjusted to approximately 7.0 by addition of diluted aqueous $\mathrm{NaOH}$. The clear solution was successively filtered through sintered glass and the polysaccharide precipitated with ethanol. TEMPO (2,2,6,6-tetramethypiperidine-1-oxyl) was supplied by Sigma Corporation.

\section{Oxidation of cashew gum}

Cashew gum was oxidized as previously reported by Sierakowski et al. ${ }^{7}$ and briefly described here. The cashew gum ( $1 \mathrm{~g}$ of polysaccharide) was dissolved in $1 \mathrm{~L}$ of distilled water. TEMPO $(0.020 \mathrm{~g}$ or $0.13 \mathrm{~mol})$ and $\mathrm{NaBr}(0.1 \mathrm{~g}$ or 0.95 mmol) were added and the solution on stirring was cooled in an ice bath and maintained at $5 \pm 1{ }^{\circ} \mathrm{C}$. A $15 \%$ sodium hypochlorite solution $(6 \mathrm{~mL}$ or $12.5 \mathrm{mmol}$ ) was added to the polymer solution, then the $\mathrm{pH}$ was adjusted to 9.3 with $2 \mathrm{~mol}$ $\mathrm{L}^{-1} \mathrm{HCl}$ solution. During the oxidation process $(1 \mathrm{~h})$ the $\mathrm{pH}$ was maintained at 9.3 by addition of a $0.05 \mathrm{~mol} \mathrm{~L}^{-1}$ aqueous $\mathrm{NaOH}$ solution. To stop the reaction sodium borohydride (50 $\mathrm{mg}$ ) was added and the reduction process was effected for 45 $\min$. The $\mathrm{pH}$ of the mixture was adjusted to 8 by addition of $\mathrm{HCl}$, and the polyelectrolyte precipitated with 2 volumes of $\mathrm{EtOH}$ in presence of $\mathrm{NaCl}$ (up to $10 \mathrm{~g} \mathrm{~L}^{-1}$ ). The product (CGOX) was isolated by centrifugation, washed several times with $\mathrm{EtOH}$, filtered, dried, and its yield was calculated.

Characterization of unmodified and oxidized cashew gum

\section{Analytical data}

$\mathrm{CG}$ and CGOX were hydrolyzed with TFA at $100{ }^{\circ} \mathrm{C}$ for $6 \mathrm{~h}$. To eliminate the excess of acid, $\mathrm{MeOH}$ was added $(5 \times 5 \mathrm{~mL})$. A HPLC Shimadzu equipment, with a Phenomenex column Rezex $8 \mu 8 \%$ H. Org. Acid $(7.8 \times$ $300 \mathrm{~mm}$ ), flow $0.5 \mathrm{~mL} \mathrm{~min}^{-1}$ and $8 \mathrm{mmol} \mathrm{L}^{-1} \mathrm{H}_{2} \mathrm{SO}_{4}$ as eluent was used to analyze the hydrolyzed material. A differential refractometer was employed as detector.

The uronic acid content was measured after samples hydrolysis and subsequent reaction with 3-hydroxybiphenyl, considering the absorbance at $520 \mathrm{~nm}$. A galacturonic and glucuronic standard curves (absorbance $v s$ concentration) was used. ${ }^{24}$

\section{Infrared spectral analysis}

The Fourier transform IR spectra (FT-IR) were recorded with a Shimadzu IR spectrophotometer (model 8300 ) in the wavenumber range of 400 and $4000 \mathrm{~cm}^{-1}$ and with samples as $\mathrm{KBr}$ pellet. 
Nuclear Magnetic Resonance (NMR)

${ }^{13} \mathrm{C}$ NMR spectra of $5 \%(\mathrm{~m} / \mathrm{v})$ solutions in $\mathrm{D}_{2} \mathrm{O}$ at $80{ }^{\circ} \mathrm{C}$ were recorded in a Bruker Model Avance DRX500 spectrometer. Chemical shifts were given in values relative to DSS at $0 \mathrm{ppm}$. A distortionless enhancement through polarization transfer (DEPT) spectrum was recorded in order to determine the multiplicity of carbon peaks; the acquisition and delay times were $1.0 \mathrm{~s}$. DEPT spectrum was obtained with final ${ }^{1} \mathrm{H}$ pulse flip angle of $135^{\circ}$ (DEPT 135). The signals in the ${ }^{13} \mathrm{C}$ NMR spectrum were assigned based on literature data for correlated compounds. ${ }^{17}$ For the NMR experiments ${ }^{1} \mathrm{H}$ (number of scans, ns $=8$ ), ${ }^{13} \mathrm{C}$ $\mathrm{BB}(\mathrm{ns}=6000)$ and ${ }^{13} \mathrm{C}$-DEPT $\left(\theta=135^{\circ}\right.$, ns $\left.=3000\right)$.

\section{Molar mass distribution}

The molar mass distribution was estimated by gel permeation chromatography (GPC) with Shimadzu equipment at room temperature (around $28{ }^{\circ} \mathrm{C}$ ) using an Ultrahydrogel linear column $(7.8 \times 300 \mathrm{~mm})$, flow 0.5

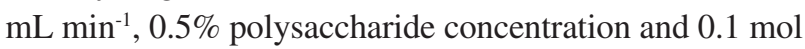
$\mathrm{L}^{-1}$ aqueous $\mathrm{NaNO}_{3}$ as solvent. A differential refractometer was used as detector.

\section{Rheological studies}

Rheological studies of $\mathrm{CG}$ and CGOX aqueous solution $(1 \%, \mathrm{~m} / \mathrm{v})$ were performed in a Rheometer Brookfield cone-plate model LV-DVIII at $25^{\circ} \mathrm{C}$. The effect of shear rate on the solutions viscosity was evaluated. The effect of temperature was investigated for $1 \%$ aqueous solutions by heating from 20 to $55^{\circ} \mathrm{C}$, with measurement of viscosity at shear rate $768 \mathrm{~s}^{-1}$ and in interval of $3{ }^{\circ} \mathrm{C}$.

\section{Thermal analysis}

TGA measurements of samples were carried out using a Shimadzu TGA-50 instrument at a heating rate of $10^{\circ} \mathrm{C}$ $\mathrm{min}^{-1}$ over a temperature range of $25-900{ }^{\circ} \mathrm{C}$. The flow

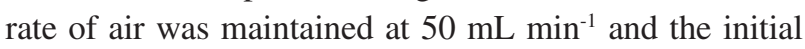
sample weight was $10 \mathrm{mg}$.

\section{Results and Discussion}

\section{Analytical data}

The yield of the oxidation product of cashew gum (96\%) is in the range of those found for the oxidation with TEMPO of most polysaccharide, such as pullulan, amylopectin, amylose, starchs, hyaluronan, scleoroglucan, inulin and chitosan (87-100\%). ${ }^{2}$

The uronic acid content, determined by colorimetric titration, was $7.2 \mathrm{~m} \%$ for unmodified cashew gum, slightly superior than the range reported in previous work (4.7-
$6.3 \%) .{ }^{16,17}$ After oxidation, this content increased to $36 \pm$ $3 \%$. The uronic acid content could be used to calculate the degree of oxidation (DO), expressed as the average fraction of modified monosaccharide unit. The calculated DO of cashew gum is 0.27 . The DO sometimes is determined based not on the total monosaccharide unit but on the free units. ${ }^{7}$ Taking in consideration the probable fragment of the cashew gum polysaccharide structure, as proposed by Anderson and Bell ${ }^{25}$ with adaptation due to further study with Brazilian gum, ${ }^{17}$ shown in Figure 2, the free galactose, glucose and mannose (bold letter) represent about $40 \%$ of total monosaccharide units. The new DO for cashew gum, calculated on the base of free units, is 0.68 . Comparison of this result with those reported for galactomanans oxidized by the same experimental procedure ${ }^{7}$ could be seen in Table 1. The DO (from free units) obtained to CGOX is in the same order of magnitude of Leucaena galactomannan and higher than the DO of Cassia fastuosa gum.

The analysis by HPLC of unmodified CG after hydrolysis (data not shown) confirms the presence of glucuronic acid, as detected previously. ${ }^{17,25}$ In the CGOX

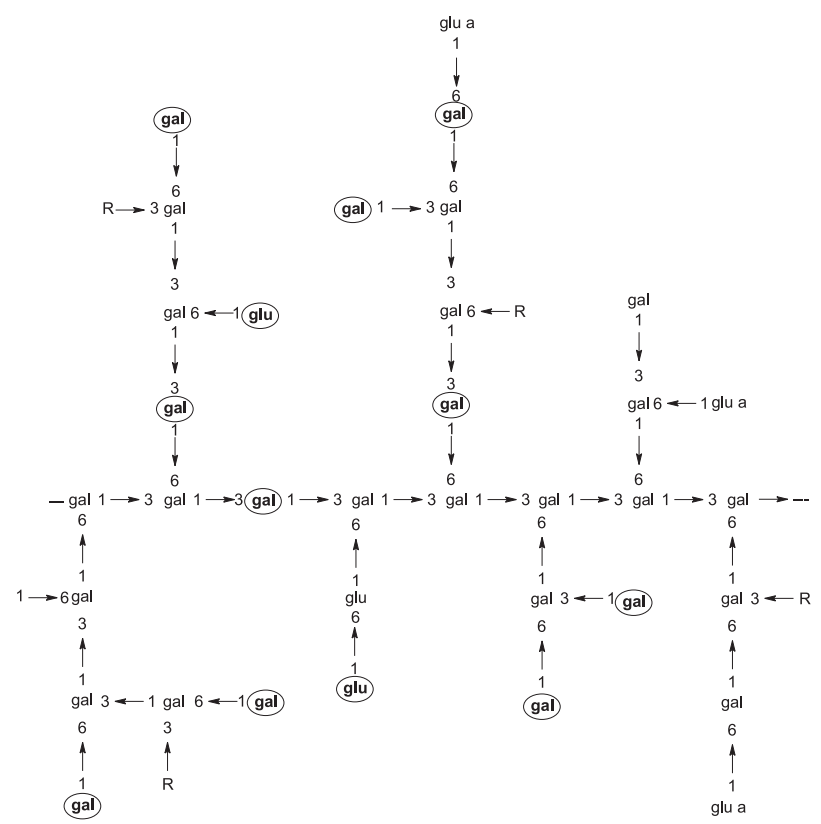

Figure 2. A possible structural fragment from unmodified cashew. R represents D-mannose, L-rhamnose, L-arabinose or 1,2-linked arabinose chains. Monosaccharides marked are those with structural requirements to be oxidized.

Table 1. Comparison among degree of oxidation of different polysaccharides

\begin{tabular}{lccc}
\hline Sample & $\mathrm{DO}^{\mathrm{a}}$ & $\mathrm{DO}^{\mathrm{b}}$ & Reference \\
\hline cashew gum & 0.27 & $\sim 0.68$ & present work \\
Cassia fastuosa galactomannan & 0.13 & 0.22 & 7 \\
Leucaena galactomannan & 0.48 & 0.62 & 7 \\
\hline
\end{tabular}

aaverage fraction of modified monosaccharide unit on the total units; baverage fraction of modified monosaccharide unit on the free units. 
chromatogram, the peak of glucuronic acid remains and one attributed to galacturonic acid appears. The content of each uronic acid in oxidized gum was not calculated, but the proportion of the peak areas indicates that the oxidation was mostly done in C-6 of galactose to lead galacturonic acid.

\section{Infrared spectroscopy}

The oxidized CG sample and starting gum were obtained in salt form. The FT-IR spectra of CG and CGOX show similar bands, such as those at $3700-3000 \mathrm{~cm}^{-1}(\mathrm{OH}$ stretching vibration), 2924 and $2893 \mathrm{~cm}^{-1}$ (symmetric and asymmetric $\mathrm{CH}$ stretching), $1415 \mathrm{~cm}^{-1}$ (OH bending), and $1200-800 \mathrm{~cm}^{-1}$ (C-O and C-C stretching vibrations of the hexopyranosyl) (Figure 3). Spectral differences could be seen in the bands at 1620 and $1430 \mathrm{~cm}^{-1}$, attributed to asymmetric and symmetric stretching of carboxylate groups. The shoulder at $1650 \mathrm{~cm}^{-1}$ could also be due to $\mathrm{OH}$ vibration from polysaccharide moisture. ${ }^{14}$ The existence of bands attributed to $-\mathrm{COO}^{-}$in unmodified $\mathrm{CG}$ spectra comes from the small amount of glucuronate (4.7$6.3 \%){ }^{16,17}$ The increase in the band intensity related to carboxylate groups of the modified gum (1620 and 1430 $\mathrm{cm}^{-1}$ ) confirms the oxidation of the polysaccharide. Galactomannan, ${ }^{7}$ Aspergillus niger and Trichoderma reesei polyuronans ${ }^{26}$ and also cellulose ${ }^{14}$ showed increase in intensity or appearance of band due to asymmetric stretching of $-\mathrm{COO}^{-}$in the same range $\left(1608-1618 \mathrm{~cm}^{-1}\right)$ after oxidation with TEMPO. The symmetric stretching was observed at $1400 \mathrm{~cm}^{-1}$ in oxidized cellulose. ${ }^{14}$

\section{NMR}

Figure 4 shows ${ }^{13} \mathrm{C}$ NMR spectra of the unmodified (CG) and oxidized cashew gum (CGOX). CG spectrum is similar to that obtained by de Paula et al., ${ }^{17}$ with signals of anomeric carbons of $\beta$-D-galactose $(1 \rightarrow 3)$ (104.4 ppm), $\beta$-D-galactose $(1 \rightarrow 6)$ (105.3 ppm), $\alpha$-Dglucose (101.1 ppm), $\alpha$-L-arabinose (105.5 ppm); $\alpha$ L-rhamnose (101.7 ppm) and $\beta$-D-glucuronic acid (103.5 ppm). A DEPT $135^{\circ}$ experiment was used to identify the oxymethylene groups as in this pulse sequence signals of the carbons bearing two protons have opposite amplitude to the $\mathrm{CH}$ and $\mathrm{CH}_{3}$ carbons (Figure 5a). It can be depicted from Figure 5a four signals at chemical shift at 61.3 and $62.4 \mathrm{ppm}$ arise from $\mathrm{CH}_{2} \mathrm{OH}$ groups. $\mathrm{CH}_{2}$ signal observed at $70.3 \mathrm{ppm}$ is due to 6-O-substitution of galactose that shift primary carbons in the range of 6-11 ppm. ${ }^{17}$ Signal from carbonyl groups was not observed at the spectrum of

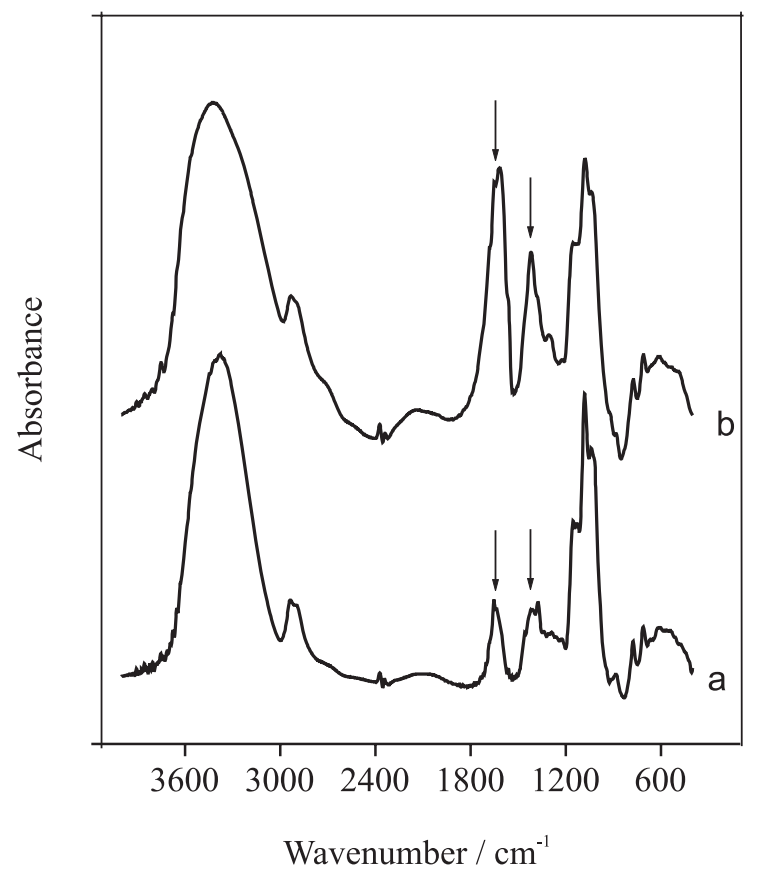

Figure 3. Infrared spectra of: (a) unmodified and (b) oxidized cashew gum in salt form.

CG (Figure 4a) due to the low proportion of this unit in unmodified gum. ${ }^{13} \mathrm{C}$ NMR spectrum of oxidized gum (Figure 4b) shows a peak at 175.5 ppm due to carboxylate carbons and a drastic decrease of C-6 primary carbons in the region of 61 to $63 \mathrm{ppm}$, confirming the oxidation of primary carbons. In CGOX DEPT $135^{\circ}$ spectrum (Figure $5 \mathrm{~b}$ ) the presence of signal due to 6-O-substituted galactose units (70.3 ppm) indicates that this unit was not eliminated by TEMPOmediate oxidation reaction. The $\alpha-1,6$ linked glucose bonds present in the original starch sample are cleaved by TEMPO-mediate oxidation reaction. ${ }^{5,14}$ In the anomeric region of CGOX spectrum it can be also depicted an increase of signals at 103.4-103.7 ppm, attributed to the $\mathrm{C}-1$ of $\beta$-D-galacturonic acid, ${ }^{27}$ corroborating the HPLC results. The appearance of new peaks at 98.1 and $94.6 \mathrm{ppm}$ is consistent with chemical shift expected for $\alpha$ and $\beta$ configuration of reducing galactose end-unit ${ }^{17}$ and indicates that degradation occurs to about $8 \%$ of total anomeric carbons areas. The loss of arabinose units and some glucose units, also, confirms degradation.

The percentage of oxidation was calculated taking into account the reduction of C-6 primary signal to anomeric carbon peak areas in $\mathrm{CG}$ and CGOX. This value should be treated with caution because the spectra were recorded with continuous proton decoupling, which may affect relative intensities through differential nuclear Overhauser enhancements. ${ }^{17,28}$ A decrease of $82.7 \%$ in relative peak 


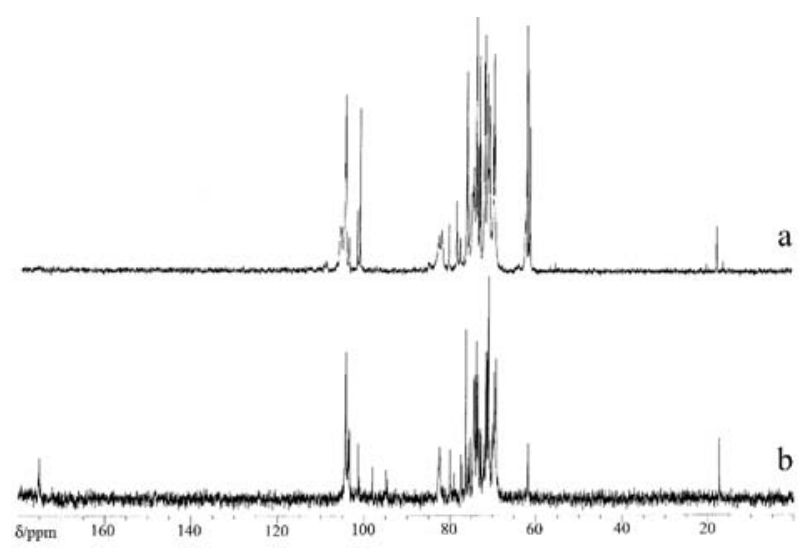

Figure 4. ${ }^{13} \mathrm{C}$ NMR spectra of: (a) unmodified cashew gum; (b) oxidized product.

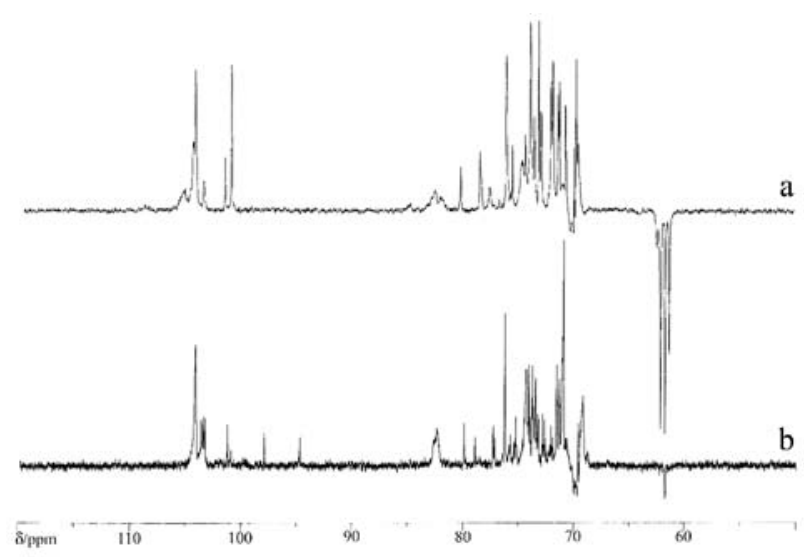

Figure 5. ${ }^{13} \mathrm{C}$ DEPT 135 NMR spectra of: (a) unmodified cashew gum; (b) oxidized product.

area and a concomitant increase of $82.4 \%$ of $\mathrm{C}-1$ of $\beta$ - Duronic acid signal was observed, indicating that oxidation occurs preferentially at primary carbons of galactose units.

\section{Molar mass distribution}

The distribution of molar mass of unmodified and oxidized CG is depicted in Figure 6. Two differences could be noted in CGOX chromatogram: shift of peak to higher elution volume $(9.26 \mathrm{~mL})$ when compared to CG $(9.15$ $\mathrm{mL}$ ) and the appearance of a shoulder at $9.93 \mathrm{~mL}$.

The oxidized polysaccharide is expected to elute at a lower volume than the starting polymer, if no chain length degradation has occurred. This is due to chain stiffening and extent, as a consequence of electrostatic repulsion of carboxylate groups. Another contribution is the increase in molar mass expected for CGOX, due to substitution of $\mathrm{CH}_{2} \mathrm{OH}$ groups (molar mass of $31 \mathrm{~g} \mathrm{~mol}^{-1}$ ) for $-\mathrm{COONa}$ (molar mass of $67 \mathrm{~g} \mathrm{~mol}^{-1}$ ) at each monosaccharide unit oxidation. The shift of oxidized gum to higher elution volume (curve b) than that unmodified gum (curve a) and

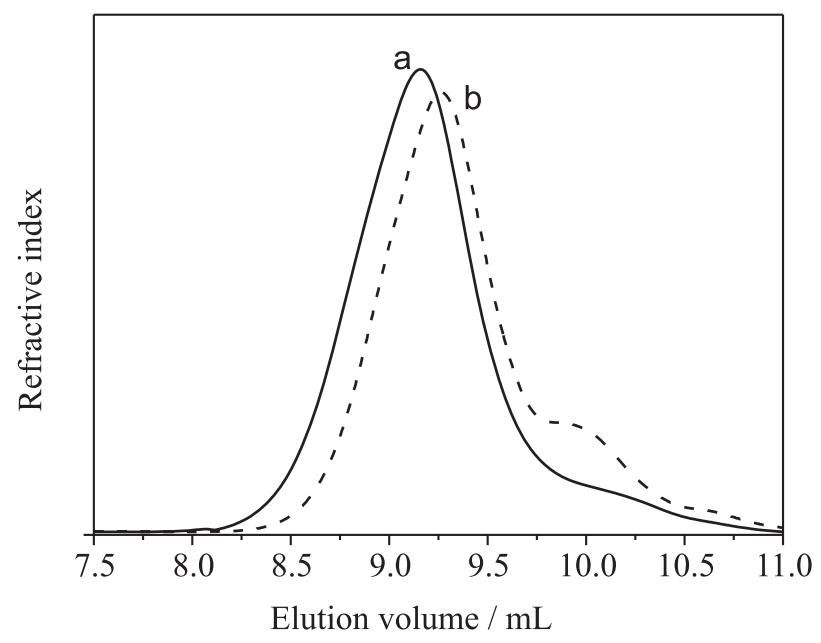

Figure 6. GPC curve of: (a) unmodified and (b) oxidized cashew gum solutions in $0.1 \mathrm{~mol} \mathrm{~L}^{-1} \mathrm{NaNO}_{3}$.

the appearance of a shoulder indicates that chain scission occurs during the oxidation.

Reduction on molar mass during the oxidation with TEMPO was also observed with other polysaccharides, such as hyaluronate, ${ }^{11}$ galactoxyloglucan ${ }^{13}$ and pullulan. ${ }^{29}$ The molar mass diminishing is small in pullulan and registered as to a half value in hyaluronate derivatives. In the oxidation of galactoxyloglucan a new peak in GPC chromatogram also appears in elution volume higher than the original gum.

\section{Thermal analysis}

Thermogravimetric curves of oxidized cashew gum are depicted in Figure 7a. The curve in solid line represents the analysis of CGOX as obtained from procedure described in experimental section. The high residual mass at $900{ }^{\circ} \mathrm{C}(9.8 \%)$ and the mass lost at temperature higher than $600{ }^{\circ} \mathrm{C}$ indicate that the oxidized sample contains impurities not eliminated during the experimental procedure. To confirm this assumption the CGOX sample was dialyzed against distilled water at ambient temperature until the conductivity of water reaches the original distilled water value $\left(3 \mathrm{mS} \mathrm{cm}^{-1}\right)$ and then freeze dried. The TGA curve of dialyzed CGOX sample was exhibited in Figure $7 \mathrm{a}$ as dash line. The residual mass at $900{ }^{\circ} \mathrm{C}$ diminishes to $4.4 \%$ and the event in the ranges $800-900{ }^{\circ} \mathrm{C}$ disappeared in purified oxidized gum. This is a confirmation of the presence of impurities in CGOX sample.

The impurities could be originated from cashew gum and/or from the oxidation process. The original unmodified cashew gum was dialyzed and the obtained thermogravimetric curves of samples are showed in Figure 7b. The difference between the original gum (solid line) 

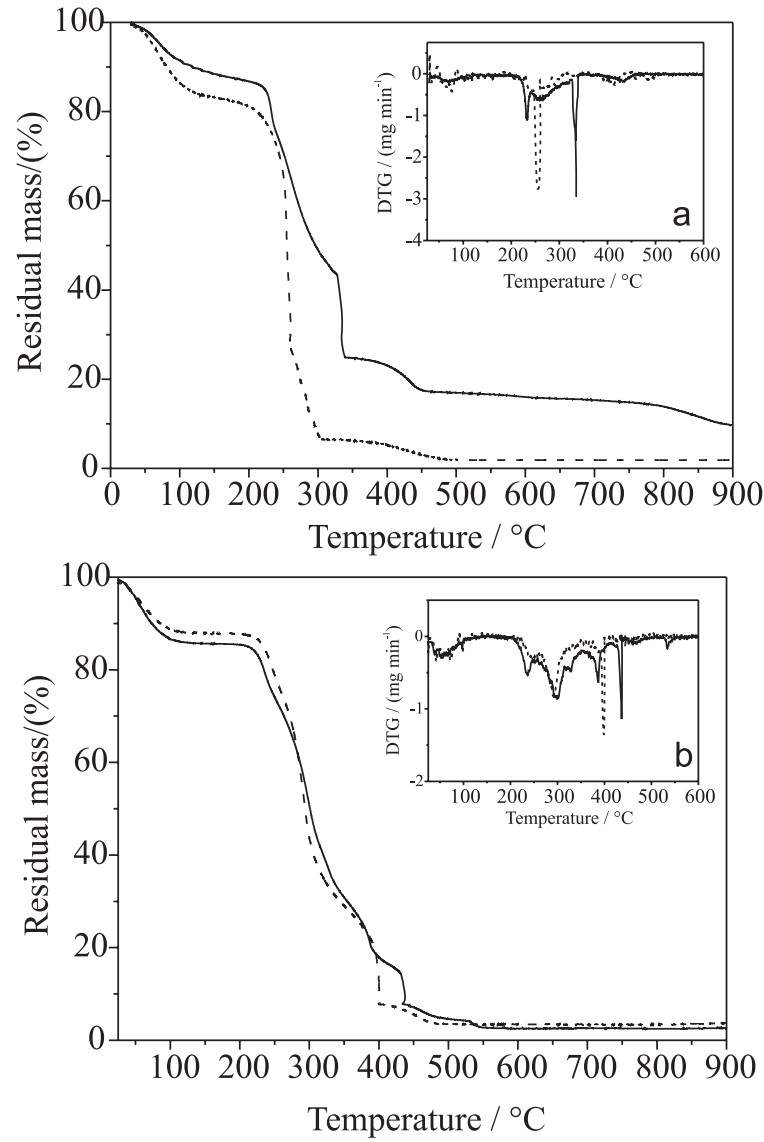

Figure 7. TGA curves of: (a) oxidized and (b) unmodified cashew gum obtained under air atmosphere. Non dialyzed gum (-) and dialyzed sample (- - ).

and the dialyzed gum (dash line) was only significant in the range of $400-4500^{\circ} \mathrm{C}$, as could be better noted in DTG curves. So, the impurities of CGOX are originated predominantly from the oxidation process and not from the starting $\mathrm{CG}$ gum.

The analysis of the experimental procedure suggests that a possible contaminant could be $\mathrm{NaCl}$. The evaporation process of this salt begins at $700{ }^{\circ} \mathrm{C}$ and finish at $850{ }^{\circ} \mathrm{C} .{ }^{30}$ The mass lost in this range of temperature is, so, attributed to the presence of $\mathrm{NaCl}$ in CGOX, estimated in around $5.3 \%$. The change in the curve profile between 250 and $450{ }^{\circ} \mathrm{C}$ is probably due to organic contaminant, remained from the oxidation procedure.

The comparison between thermograms reveals that the thermal decomposition process of CG and CGOX dialyzed samples are different. The oxidized gum presents a event of water loss (up to $150{ }^{\circ} \mathrm{C}$ ), a main degradation event, with temperature of maximum decomposition $\left(\mathrm{T}_{\mathrm{m}}\right)$ at $257^{\circ} \mathrm{C}$, a slow process of mass loss between 260 and $300{ }^{\circ} \mathrm{C}$ and a last event up to 480 ${ }^{\circ} \mathrm{C}$. Unmodified cashew gum exhibited three events, in
$\mathrm{T}_{\mathrm{m}}$ at 246,290 and $398^{\circ} \mathrm{C}$, beside the water loss up to $150{ }^{\circ} \mathrm{C}$ (Table 2). Cashew gum is a complex heteropolysaccharide and its mechanism of thermal decomposition is unknown. Generally, dehydration, depolymerization, decarbonylation and pyrolitic decomposition, with the evolution of $\mathrm{H}_{2} \mathrm{O}, \mathrm{CO}, \mathrm{CO}_{2}$, and $\mathrm{CH}_{4}$ are involved in anionic gum thermal decomposition. ${ }^{31}$ However, because of the differences in structure and functional groups, either the degradation routes or the resulting fragments will be different.

Table 2. Parameters from TGA and DTG curves of the unmodified and oxidized cashew gum after dialysis

\begin{tabular}{|c|c|c|c|c|c|c|c|}
\hline \multirow[t]{2}{*}{ Sample } & \multirow[t]{2}{*}{$\mathrm{T}_{\mathrm{i}} /{ }^{\circ} \mathrm{C}$} & \multicolumn{4}{|c|}{$\mathrm{T}_{\mathrm{m}} /{ }^{\circ} \mathrm{C}$} & \multirow{2}{*}{$\begin{array}{l}\text { residual } \\
\text { mass/(\%) }\end{array}$} & \multirow[t]{2}{*}{$\mathrm{IPDT} /{ }^{\circ} \mathrm{C}$} \\
\hline & & I & II & III & IV & & \\
\hline CG & 209 & 64 & 246 & 290 & 398 & 3.1 & 301 \\
\hline CGOX & 191 & 65 & 257 & - & - & 4.4 & 259 \\
\hline
\end{tabular}

The thermal stability is an important characteristic of materials. This stability could be determined by some parameters, such as $\mathrm{T}_{\mathrm{i}}$ (initial decomposition temperature), $\mathrm{T}_{\mathrm{m}}$, IPDT (integral procedure decomposition temperature), and others. ${ }^{32}$ The shift of $T_{i}$ and IPDT to lower temperatures demonstrates that the oxidation reduces the thermal stability of cashew gum (Table 2), as observed also with oxidized galatoxyloglucan. ${ }^{13}$ According to Viletti et al. ${ }^{33}$ in general, neutral polysaccharides showed higher thermal resistance than charged polyanions. So, the charge increase by oxidation leading to a decrease in thermal resistance could be expected.

\section{Rheological studies}

Aqueous solutions of CG and CGOX (dialyzed and not dialyzed) have low viscosity (Figure 8 ). The value of viscosity reported in literature for cashew gum solution at $1 \%(\mathrm{~m} / \mathrm{v}), 1.0 \mathrm{mPa} \mathrm{s},{ }^{16}$ is similar to that obtained in the present work. The oxidation promotes a small increase in viscosity of approximately $0.1 \mathrm{mPa}$. A higher increase was expected, if only the increase in uronic acid from 7.2 to $36 \%$ was taking into account. The higher negative charge induces more repulsion between chains and a more expanded macromolecular conformation. The smaller increase in viscosity than was supposed is, probably, due to chain scission, as already commented in GPC analysis. Another contribution could be due to the remained salt, as detected by thermogravimetric analysis. The viscosity of dialyzed sample solution is similar to that of non dialyzed gum in the shear rate range of 600 to $800 \mathrm{~s}^{-1}$. A small increase was observed in shear rate below $600 \mathrm{~s}^{-1}$. 
So, the small difference between unmodified and oxidized gum is predominantly due to chain degradation.

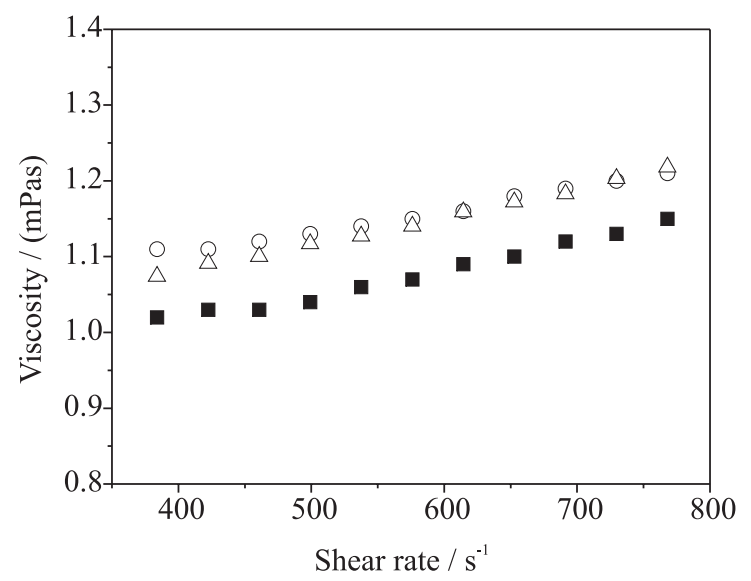

Figure 8. Effect of shear rate on the viscosity of aqueous solutions: ( unmodified cashew gum; $(\triangle)$ oxidized and non dialyzed CG; $(O)$ oxidized and dialyzed CG. Gum concentration, $1.0 \%(\mathrm{~m} / \mathrm{v})$ at $25^{\circ} \mathrm{C}$.

The expected viscosity of CGOX, if no chain scission had occurred, could be estimated based on the proposition made by Reed et al. ${ }^{34}$ that the intrinsic viscosity, [ $\eta$, of variably ionized polyacrylate varies as $\xi / \mathrm{C}_{\mathrm{s}}^{0.5}$, where $\xi$ is the Manning charge parameter and $\mathrm{C}_{\mathrm{s}}$ is the univalent electrolyte concentration in $\mathrm{mmol} \mathrm{L}^{-1}$. Taking into account a constant salt concentration, $[\eta]$ could be considered proportional to $\xi$. The following relationships are proposed:

$\frac{[\eta]_{\mathrm{CGOX}}}{[\eta]_{\mathrm{CG}}} \propto \frac{\xi_{\mathrm{CGOX}}}{\xi_{\mathrm{CG}}} \propto \frac{\% \mathrm{COO}_{\mathrm{CGOX}}^{-}}{\% \mathrm{COO}_{\mathrm{CG}}^{-}}$

The content of uronic acid is $7.2 \%$ and $36 \%$ in CG and CGOX, respectively. The intrinsic viscosity of cashew gum $^{20}$ in $0.1 \mathrm{~mol} \mathrm{~L}^{-1}$ aqueous $\mathrm{NaCl}$ is $0.84 \mathrm{dL} \mathrm{g}^{-1}$ and so, the expected $[\eta]_{\mathrm{CGOX}}$ is $4.2 \mathrm{dL} \mathrm{g}^{-1}$.

The dependence of solution viscosity with concentration for dilute solutions is given by the relation ${ }^{34}$

$\eta=\eta_{0}+[\eta] c \eta_{0}+k_{H}[\eta]^{2} c^{2} \eta_{0}$

where $\eta_{0}$ is the solvent viscosity, $\mathrm{c}$ the polymer solution concentration and $\mathrm{k}_{\mathrm{H}}$ the Huggins constant.

The equation 2 could be applied for CGOX and CG at gum concentration of $1 \mathrm{~g} \mathrm{dL}^{-1}$ and reduced to the equation 3 .

$\frac{\eta_{\mathrm{CGOX}}}{\eta_{\mathrm{CG}}}=\frac{1+[\eta]_{\mathrm{CGOX}}+\mathrm{k}_{\mathrm{H}}[\eta]_{\mathrm{CGOX}}^{2}}{1+[\eta]_{\mathrm{CG}}+\mathrm{k}_{\mathrm{H}}[\eta]_{\mathrm{CG}}^{2}}$

Taking into account that the electrostatic screening was high enough to reduce the classical increase of viscosity at low polymer concentration, $\mathrm{k}_{\mathrm{H}}$ was taken by Reed et al. ${ }^{34}$ as around 0.5 . Applying $[\eta]_{\mathrm{CGOX}}$ and $[\eta]_{\mathrm{CG}}$, as 4.2 and $0.84 \mathrm{dL} \mathrm{g}^{-1}$, respectively, and $\mathrm{k}_{\mathrm{H}}$ as 0.5 in equation 3 , the solution viscosity of CGOX without degradation was estimated as 6.4 times the viscosity of CG, both at 1 $\mathrm{g} \mathrm{dL}^{-1}$ polysaccharide concentration and ionic strength of $0.1 \mathrm{~mol} \mathrm{~L}^{-1}$. Without the addition of salt the enhancement in the viscosity of oxidized gum solution is expected to be more than 6.4 in comparison with $\mathrm{CG}$ solution. The increase in $\eta_{\mathrm{CGOX}}$ of only $10 \%$ points to the occurrence of a high degree of chain degradation.

The effect of temperature on the viscosity of $1 \% \mathrm{CG}$ and CGOX aqueous solutions was investigated at a temperature range of $20-55^{\circ} \mathrm{C}$. Arrehnius-Frenkel-Eyring equation ${ }^{35}$ was applied to the data of $\eta_{\mathrm{CGOX}}$ and $\eta_{\mathrm{CG}}$ and a plot of $\ln \eta v s . \mathrm{T}^{-1}$ (in Kelvin) was obtained (Figure 9). From the slope of the lines, it was possible to calculate the apparent activation energy of flow $\left(\mathrm{E}_{\mathrm{a}}\right)$ of 12.3 and $11.6 \mathrm{~kJ}$ $\mathrm{mol}^{-1}$ for unmodified gum and oxidized gum solutions, respectively. The $\mathrm{E}_{\mathrm{a}}$ value for $2 \%$ aqueous solution of cashew gum is $15.6 \mathrm{~kJ} \mathrm{~mol}^{-1},{ }^{16}$ characteristic of branched polysaccharide with few inter- and intra-interactions between polymer chain. ${ }^{23}$ Low value was expected for $1 \%$ solution, because $\mathrm{E}_{\mathrm{a}}$ decreases with solution concentration. ${ }^{35}$ The small activation energy of flow for oxidized gum could be due to chain degradation given molar mass less than $10^{4}$ $\mathrm{g} \mathrm{mol}^{-1}$ and the contribution of fraction of very low molar mass, as indicated by the shoulder in GPC. The molar mass of cashew gum is in the order of $10^{5} \mathrm{~g} \mathrm{~mol}^{-1} .^{20}$

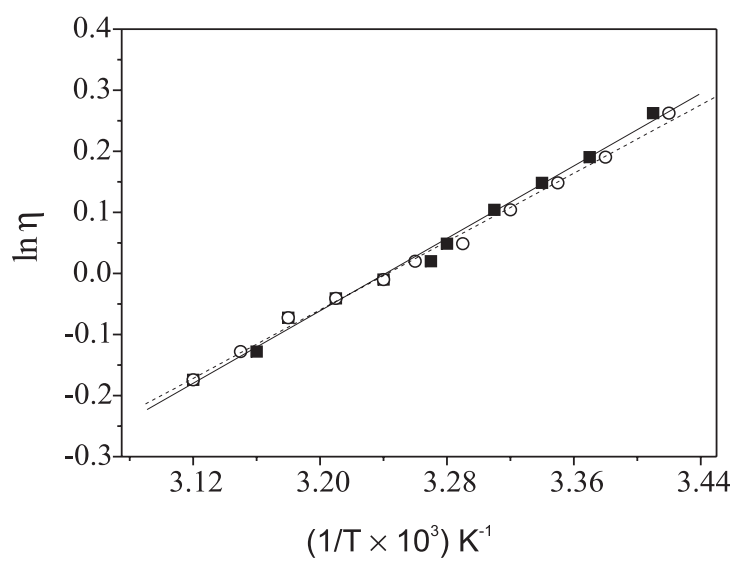

Figure 9. Effect of temperature on the viscosity of $1 \%(\mathrm{~m} / \mathrm{v})$ aqueous solution of: (-) unmodified cashew gum; (- - -) oxidized gum.

\section{Conclusions}

The oxidation of cashew gum with TEMPO has a high product yield $(96 \%)$ and promotes the increase of uronic acid content from 7.2 (starting gum) to $36 \mathrm{~m} \%$. This represents the carboxylation of $68 \%$ of the free galactose 
and glucose units. The oxidation occurs preferentially at primary carbons of galactose units. The aqueous solutions of oxidized and unmodified gum have similar low viscosity. The small augment of $10 \%$ in the solution viscosity due to oxidation is caused by the effect of high degree of chain degradation that overcomes almost all effect of chain expansion of a more negative polysaccharide formed. A less thermal stable cashew gum is obtained after the oxidation with TEMPO. The high product yield and the substantial increase in polyelectrolyte character amplify the possibility of cashew gum application, in special in those case where high molar mass or viscosity are not required.

\section{Acknowledgments}

The authors are thankful to Fundação Coordenação de Aperfeiçoamento do Pessoal de Ensino Superior (CAPES-Brazil) for the fellowship and scientific cooperative program (PROCAD), and Conselho Nacional de Desenvolvimento Científico e Tecnológico (CNPqBrazil). The authors also wish to acknowledge CENAUREMN (Federal University of Ceará) for recording NMR spectra.

\section{References}

1. De Nooy, A. E. J.; Besemer, A. C.; van Bekkum, H.; Tetrahedron 1995, 51, 8023.

2. Bragd, P. L.; van Bekkum, H.; Besemer, A. C.; Top. Catal. 2004, $27,49$.

3. De Souza, M. V. N.; Quim. Nova 2004, 27, 287.

4. Anelli, P. L.; Biffi, C.; Montanari, F.; Quici, S.; J. Org. Chem. 1987, 52, 2559

5. Kato, Y.; Matsuo, R.; Isogai, A.; Carbohydr. Polym. 2003, 51, 69.

6. Sierakowski, M.-R.; Milas, M.; Desbrières, J.; Rinaudo, M.; Carbohydr. Polym. 2000, 42, 51.

7. Sierakowski, M.-R.; Freitas, R. A.; Fujimoto, J.; Petri, D. F. S.; Carbohydr. Polym. 2002, 49, 167.

8. De Nooy, A. E. J.; Besemer, A. C.; van Bekkum, H.; Carbohydr. Res. 1995, 269, 89.

9. Muzzarelli, R. A. A.; Muzzarelli, C.; Cosani, A.; Tjerbojevich, M.; Carbohydr. Polym. 1999, 39, 361.

10. Chang, P. S.; Robyt, J. F.; J. Carbohydr. Chem. 1996, 15, 819.

11. Jiang, B.; Drouet, E.; Milas, M.; Rinaudo, M.; Carbohydr. Polym. 2000, 327, 455.

12. De Nooy, A. E. J.; Rori, V.; Masci, G.; Dentini, M.; Crescenzi, V.; Carbohydr. Res. 2000, 324, 116.

13. Freitas, R. A.; Martin, S.; De Paula, R. C. M.; Feitosa, J. P. A.; Sierakowski, M.-R.; Thermochim. Acta 2004, 409, 41.
14. Perez, D. S.; Montanari, S.; Vignon, M. R.; Biomacromolecules 2003, 4, 1417.

15. Rodrigues, J. F.; De Paula, R. C. M.; Costa, S. M. O.; Polímeros: Ciência e Tecnologia 1993, jan/mar, 31.

16. De Paula, R. C. M.; Rodrigues, J. F.; Carbohydr. Polym. 1995, 26, 177.

17. De Paula, R. C. M.; Heatley, F.; Budd, P. M.; Polym. Int. 1998, $45,27$.

18. Guilherme, M. R.; Reis, A. V.; Takahashi, S. H.; Rubira, A. F.; Feitosa, J. P. A.; Muniz, E. C.; Carbohydr. Polym. 2005, 61, 464.

19. Maciel, J. S.; De Paula, R. C. M.; Paula, H. C. B.; Miranda, M. A. R.; Sasaki, J. M.; J. Appl. Polym. Sci. 2006, 99,326.

20. Silva, D. A.; De Paula, R. C. M.; Feitosa, J. P. A.; De Brito, A. C. F.; Maciel, J. S.; Paula, H. C. B.; Carbohydr. Polym. 2004, $58,163$.

21. http://caju.cnpat.embrapa.br/pif/sistemas/01.htm, accessed in November 2005.

22. Bandeira, C.T.; Relatório Técnico da Empresa Brasileira de Pesquisa Agropecuária - EMBRAPA-CNPCa, 1991, 6,1.

23. De Paula, R. C. M.; Santana, S. A.; Rodrigues, J. F.; Carbohydr. Polym. 2001, 44, 133.

24. Blumenkrantz, N.; Asboe-Hansen, G.; Anal. Biochem. 1973, $54,484$.

25. Anderson, D. M. W.; Bell, P. C.; Anal. Chim. Acta 1975, 79, 185.

26. Muzzarelli, R. A. A.; Miliani, M.; Cartolari, M.; Tarsi, R.; Tosi, G.; Muzzarelli, C.; Carbohydr. Polym. 2000, 43, 55.

27. Bock, K.; Pedersen, C. In Advances in Carbohydrate Chemistry and Biochemistry; Tipson, R. S.; Horton, D., eds.; Academic Press: 1983, vol. 41, p. 27.

28. Howarth, O. R. In NMR Spectroscopy of Polymers; Ibbett, R., ed.; Blackie: Glasgow, 1994, ch. 4.

29. De Nooy, A. E. J.; Besemer, A. C.; van Bekkum, H.; van Dijk, J. A. P. P.; Smith, J. A. M.; Macromolecules 1996, 29, 6541.

30. Liptay, Dv. G.; Atlas of Thermoanalytic Curves, Heyden\&Son Ltd: London, 1973, vol. 1.

31. Zohurian, M. J.; Shokrolahi, F.; Polym. Test. 2004, 23, 575.

32. Cunha, P. L. R.; Castro, R. R.; Rocha, F. A. C.; De Paula, R. C. M.; Feitosa, J. P. A.; Int. J. Biol. Macromol. 2005, 37, 99.

33. Viletti, M. A.; Crespo, J. S.; Soldi, M. S.; Pires, A. T. N.; Borsali, R.; Soldi, V.; J. Therm. Anal. Calorim. 2002, 67, 295.

34. Reed, W. F.; Ghosh, S.; Medjahdi, G.; François, J.; Macromolecules 1991, 24, 6189.

35. Vinogradov, G. V.; Malkin, A. Ya.; Rheology of Polymers, Viscoelasticity and Flow of Polymers, Mir: Moscow , 1980, pp. 105-121.

Received: December 28, 2005 Web Release Date: November 7, 2006 